\title{
AIDS and Social Exclusion: Personality Features or Adaptive Behaviors?
}

\author{
Enrique Flores Sarazúa, Mercedes Borda Más, \\ and $\mathrm{M}^{\mathrm{a}}$ Ángeles Pérez San Gregorio \\ University of Seville
}

\begin{abstract}
The purpose of this survey is to detect common personality features in people infected with AIDS who have a case history of drug addiction and who live in a situation of social exclusion. The sample comprised 105 male participants from the Autonomous Community of Andalusia, divided into 4 groups: (a) 30 men with AIDS, having an intravenous drug addiction case history and who live in a condition of social exclusion; (b) 30 men with IVDA case history, also living in a situation of social exclusion; (c) 15 men in a social exclusion condition; and (d) 30 men in a condition of social adaptation. The evaluation instruments were an author-designed semi-structured interview and the Multiaxial Clinical Inventory (MCMI-II; Millon, 1987). Although some differences were found, the results indicate that there is no specific personality profile in the "social exclusion" population. People in a condition of social exclusion (AIDS, drug addicts, and poor people) may obtain similar scores in the variables studied, but there is no clear specific personality profile in the excluded population, although there may be certain situations in which the segregated groups present similar behaviors. Furthermore, these behaviors do not always correspond to personality features but are adaptive responses to a harsh and complex reality.
\end{abstract}

Keywords: personality variables, AIDS, social exclusion, Millon Clinical Multiaxial Inventory MCMI-II

El objetivo de este estudio es detectar rasgos comunes de personalidad en personas afectadas por el SIDA con antecedentes de drogadicción y que viven en una situación de exclusión social. La muestra está formada por 105 varones de la Comunidad Autónoma Andaluza, distribuida en cuatro grupos: (a) 30 personas con SIDA, con historial de adicción a drogas vía parenteral (ADVP) y que viven en una situación de exclusión social; (b) 30 personas con historial de ADVP y en situación de exclusión social; (c) 15 personas en situación de exclusión social y (d) 30 personas en situación de adaptación social. Las medidas de evaluación fueron: Entrevista semiestructurada de elaboración propia y el Inventario Multiaxial Clínico de Millon MCMI-II (Millon, 1987). Los resultados indican que, a pesar de las diferencias encontradas, no existe un perfil de personalidad específico en la población de "exclusión social". En general, las personas en situación de exclusión social (grupos SIDA, drogadicción y pobreza) presentan puntuaciones similares en las variables estudiadas, pero ello no indica de forma clara que exista un perfil de personalidad en la población de exclusión, sino que tal vez debido a determinadas situaciones, los grupos de excluidos presenten conductas similares y que dichos comportamientos no siempre corresponden a rasgos de personalidad sino a respuestas adaptativas a una compleja y dura realidad.

Palabras clave: variables de personalidad, SIDA, exclusión social, Inventario Multiaxial Clínico Millon MCMI-II

Correspondence concerning this article should be sent to: Mercedes Borda Mas, Departamento de Personalidad, Evaluación y Tratamiento Psicológicos, Facultad de Psicología, C./ Camilo José Cela, s/n, 41018 Sevilla (Spain). Phone: 954557806/6939. FAX: 954557807. E-mail: mborda@us.es

Translation: Virginia Navascués Howard 
The hypothesis that defends the relation between stress, the immunological system, and personality disorders has become increasingly influential in the last few years for research on individual differences (Fuste \& Ruíz, 2000a). In this sense, already in 1984, Jemmot and Locke expressed the idea of evaluating these variables in research on psychoimmunology and, subsequently, Eysenck concluded that people with low scores on neuroticism and psychoticism, and high scores on extroversion are genetically predisposed to presenting patterns of depression and helplessness in stressing situations, thus producing an increase in the levels of cortisol in blood, which has an immunodepressor effect (Eysenck, 1985). However, recently, more emphasis has been placed on the need to analyze the role of individual differences in psychoimmunology (Benschop, Jabaaij, Oostveen, Vingehoets, \& Bailliex, 1998) and, in fact, to consider them a tool to better understand the relations between stress, behavior, and the immunological response, given that some authors regard these differences as a possible explanation of the low effect of some stressors on the immune response (Kwang et al., 1998).

In spite of this, except for some studies such as those of Fuste and Ruíz (2000b), Iraurgi (2003), and Thornton, Tropo, and Burgess (2000), among others, there has been little recent research addressing the evaluation of personality dimensions in relation to the immune system. However, some investigations have used, for example, the number of antibodies as a measure of immunological activity and have found a positive and significant relation between neuroticism and leucocytes in blood (Jemmot \& Locke, 1984). However, most of the works reviewed do not measure the functionality of the immune system itself, although some authors infer it from the presence or absence of specific symptomatology of certain infectious diseases or from the number of cells or parameters of the immune system (number of lymphocytes, quantity of immunoglobins, number of leucocytes) in a blood sample. None of these measures represents the specific response of the immune system (Roitt, 1988).

Regarding the infection from HIV/AIDS, some studies mention that the evolution of the emotional response in persons with HIV/AIDS will depend on personality disorders prior to the diagnosis (Ayuso, 1997; Combs \& Livingston, 2001; Valverde, 1996), which leads to the speculation that the presence of personality disorders may substantially affect the course of HIV/AIDS. However, although the possible causality of HIV/AIDS is clear in some psychopathologic alterations, in personality disorders, HIV/AIDS has only been included as one of the etiological factors in people with HIV/AIDS who present cognitive deterioration or AIDS dementia-type degenerative processes (Lluch, Salvador, Gatell, \& Cirera, 1989; Salvador, Lluch, \& Ayuso, 1995).

In this sense, despite some investigations focused on personality disorders in people with HIV/AIDS, such studies are very scarce, as is the large number of factors that remain to be clarified in this field (Fuste \& Ruíz, 2000b).
Specifically, the diagnosis of personality disorders in persons with HIV/AIDS is particularly complex, owing in part to the intrinsic difficulties of evaluating personality problems, and also to the high frequency of these disorders in highrisk groups (especially in the group of intravenous drug addicts) and to the difficulty of the differential diagnosis of functional and organic disorders in this population (Salvador et al., 1995).

However, despite these difficulties, there are some studies on the prevalence of personality disorders in the population infected with HIV/AIDS. Thus, Rundell, Wise, and Ursano (1986), using criteria from the Diagnostic and Statistical Manual of Mental Disorders, third edition (American Psychiatric Association, 1980), found that $18 \%$ of the people with HIV/AIDS presented a personality disorder as the main diagnosis (an antisocial disorder and a personality disorder plus a catastrophizing reaction to the diagnosis) and $9 \%$ received an additional diagnosis of some personality disorder, probably of an organic type. In a controlled study, Perkins, Davidson, Leserman, Liao, and Evans (1993) evaluated 58 asymptomatic seropositive and 53 seronegative homosexuals, finding a significantly higher prevalence of personality disorders among the seropositive persons (33\%) compared with the seronegative individuals $(15 \%)$. Moreover, there were higher levels of emotional distress in the sample of seropositive people who also had personality disorders.

In psychiatric populations of people with HIV/AIDS, in a study of a sample of 50 people with HIV who were inpatients of the Psychiatric Service, Ayuso, Lastra, and Montañés (1995) found a prevalence of $12 \%$ of personality disorders. Navia and Price (1987) reported changes in personality in $37.9 \%$ of a sample of 112 patients with AIDSdementia.

In general, personality disorders are more frequent in individuals infected with HIV/AIDS than in the rest of the population and, specifically, the borderline personality disorder presents the highest prevalence of HIV/AIDS (Perkins et al., 1993), a fact that subsequent investigations have confirmed. In fact, in a longitudinal study, Jacobsberg, Frances, and Perry (1995) observed that approximately 2/5 of the seropositive subjects could be diagnosed as having a personality disorder. These individuals did not know they were HIV carriers, which makes HIV infection an unbiased "expected response" variable. Similarly, in the study of Brooner, Herbst, and Schmidt (1993), the presence of an antisocial personality disorder was observed in $30-50 \%$ of the sample that abused opiates, and these people presented higher rates of HIV infection and more behavioral disorders than drug dependent individuals without personality disorders.

An explanation of this higher incidence of certain personality disorders in the HIV/AIDS population was offered recently by Millon and Davis (2000). According to these authors, personality disorders are usually associated with higher impulsivity, which has been linked to high risk 
behaviors. By definition, impulsive individuals do not tend to think about the consequences of their acts. Thus, for example, people with a borderline personality usually experience sudden emotional changes and perform impulsive acts, such as alcohol and substance abuse. Moreover, people with high impulsivity have been observed to engage in many sexual relations and, in most instances, without taking prophylactic measures, and this is one of the so-called high risk behaviors in HIV contagion. Similarly, among individuals with an antisocial personality disorder, there is a significantly higher proportion who shares needles. In addition people with a narcissistic personality disorder may have feelings of "invulnerability" and therefore, they do not believe in preventive measures against HIV. Conversely, people with a dependent personality disorder may have trouble refusing to engage in high risk behaviors (sharing needles, sex without protection). And lastly, individuals with sadistic traits may infect others deliberately, and people with an antisocial personality disorder may lie about their sexual antecedents or about their HIV or AIDS condition (Millon \& Davis, 2000).

Despite the investigations reviewed, more studies are needed to contrast other hypotheses that relate certain psychological variables with HIV/AIDS. Therefore, the goals of our investigation are to examine in detail the behavior of several psychological variables in the collective of persons infected with HIV/AIDS. Specifically, the main purpose of this work is to detect common personality traits in persons affected by AIDS, who also have antecedents of drug addiction and who live in a situation of social exclusion.

\section{Method}

\section{Participants}

This investigation was carried out from the $29^{\text {th }}$ of September, 2001, until the $16^{\text {th }}$ of March, 2003. A total of 105 men from the Autonomous Community of Andalusia, with a high percentage of residents of Seville, participated in this research. The sample was distributed into various groups. The first group (AIDS group) was made up of 30 men infected with HIV, AIDS category, mean age of 40.63 years $(S D=5.39)$, who presented a history of drug addiction and who lived in a situation of social exclusion ${ }^{1}$. The second group (drug addiction group) was comprised of 30 men whose mean age was 40.53 years addiction $(S D=10.21)$, who also had a history of drug dependence and who lived in a social situation of exclusion. The third group (poverty group) was made up of 15 men, mean age 42.2 years ( $S D$ $=9.27$ ) living in a situation of social exclusion, and the fourth group (normal group) comprised 30 men whose mean age was 34.47 years $(S D=6.20)$, with no detected pathology, and living in a situation of social adaptation. In order to have access to the excluded groups, we contacted associations that are involved in the field of social exclusion and, in the case of the participants of the normal group, we interviewed people from social adaptation settings.

The following participant sociodemographic characteristics were observed when comparing the excluded groups. The ages in the various groups were very similar (around 40 years old). Regarding habitual domicile, at the time of evaluation, most of the participants were transients at centers, with the period of residence being longer for the AIDS group than for the remaining excluded groups. As for economic income, it was noteworthy that hardly any participants earned more than 300 a month, and, if so, the source was generally nontaxable pensions and activities such as mendacity, unlawful activities, car-parking, etc. Family contact was sporadic or inexistent. Most of the participants from the normal group lived with their family $(66.7 \%)$, with an income of over 600 per month $(73.3 \%)$ that they earned with their own work $(83.3 \%)$.

In the AIDS group, which represents the collective under study, $70 \%$ of the participants presented an evolution of the infection of more than 11 years, and $89.9 \%$ of the sample was at an advanced stage of AIDS. According to the information provided by the participants, the most frequent means of contagion was intravenous. At the time of evaluation, $70 \%$ of the participants were undergoing antiretroviral treatment, and $100 \%$ had visited the specialist for a medical check-up less than 6 months ago. The participants suffered an average of 1.07 diseases per person, the most frequent being hepatitis. Regarding treatments received, when adding the different treatments and multiplying the mean habitual dose, the approximate total number of pills ingested daily was 16 pills per participant.

Lastly, with regard to the variables involving drug problems, in the AIDS group, most of the participants acknowledged a history of polydrug consumption, and $90 \%$ also acknowledged having used all administration routes. The total duration of drug consumption was very similar in the AIDS and drug addiction groups. However, participation of the AIDS group in the Methadone Maintenance Program was much higher, $86 \%$, receiving a mean amount of 85 $\mathrm{mg} /$ day of methadone.

\footnotetext{
1 To delimit the concept of social exclusion, we used the recent proposal of Pérez, Sáez, and Trujillo (2002). These authors operationalize exclusion by means of various dimensions: on the one hand, the so-called general dimensions (home, work, and education) and, on the other, the so-called specific situations (polyaddictions, problems with justice, the physically and psychologically disabled, and health). In our work, these dimensions were measured and classified via several variables collected in the semistructured interview elaborated by the first author (Flores, 2004). The content of this interview is described in the text.
} 


\section{Instruments}

Selection of the psychological evaluation instruments was quite complex. It was necessary to take into account not only the appropriateness of the instrument to our goals, but also that the instrument should match the special characteristics of the various samples, such as low cultural level, high social desirability, high level of sedation and physical deterioration, and low level of attention. Moreover, the multi-problematic situation in which these populations live made it necessary to evaluate a large number of variables. We therefore designed a psychological evaluation protocol comprising the following instruments:

Semistructured Interview (Flores, 2004). The interview was elaborated by the first author to gather data about the areas considered relevant for our study. The items are grouped into five blocks: sociodemographic data, physical health data, drug addiction data, mental health data, and sociojudicial data. As this was the first instrument to be administered in the protocol, it had a two-fold purpose: on the one hand, to obtain pertinent information, and on the other, to establish a minimum personal bond with the individual before administering the remaining psychological evaluation material.

Millon Multiaxial Clinical Inventory (MCMI-II; Millon, 1987). This is a self-report, which is coordinated with the disorders included in the DSM-III and the DSM-III-R
(American Psychiatric Association, 1980, 1987), especially the disorders from Axis II. The main purpose of the MCMIII is to provide clinical practitioners with information about the evaluation and treatment of patients with emotional and interpersonal difficulties.

In order to interpret the profile, it is necessary to separate the scales that belong to the basic clinical personality pattern ( 1 to $8 \mathrm{~B}$; see Table 1), scales than indicate the presence of a severe pathological personality $(\mathrm{S}, \mathrm{C}$, and $\mathrm{P})$, scales that indicate moderate syndromes (A to T), and scales that indicate severe or psychotic clinical syndromes (SS, CC, and PP). However, in this study, we only included the 10 scales corresponding to the basic clinical personality pattern. Figure 1 displays the mean scores of the different experimental groups in each scale.

Although this inventory is a self-report, as the participants' cultural level (in the three exclusion groups) made it more difficult for them to comprehend the text, we decided that the evaluator should read the items and the possible responses in all cases.

In the original version of the MCMI-II, the internal consistency indexes were higher than .80 for all the scales (Millon, 1987). In this study, we used the Spanish adaptation (TEA, 1999). The reliability indexes (Cronbach's alpha) for the Spanish validation of the MCMI-II for the scales employed were between .70 and .90 .

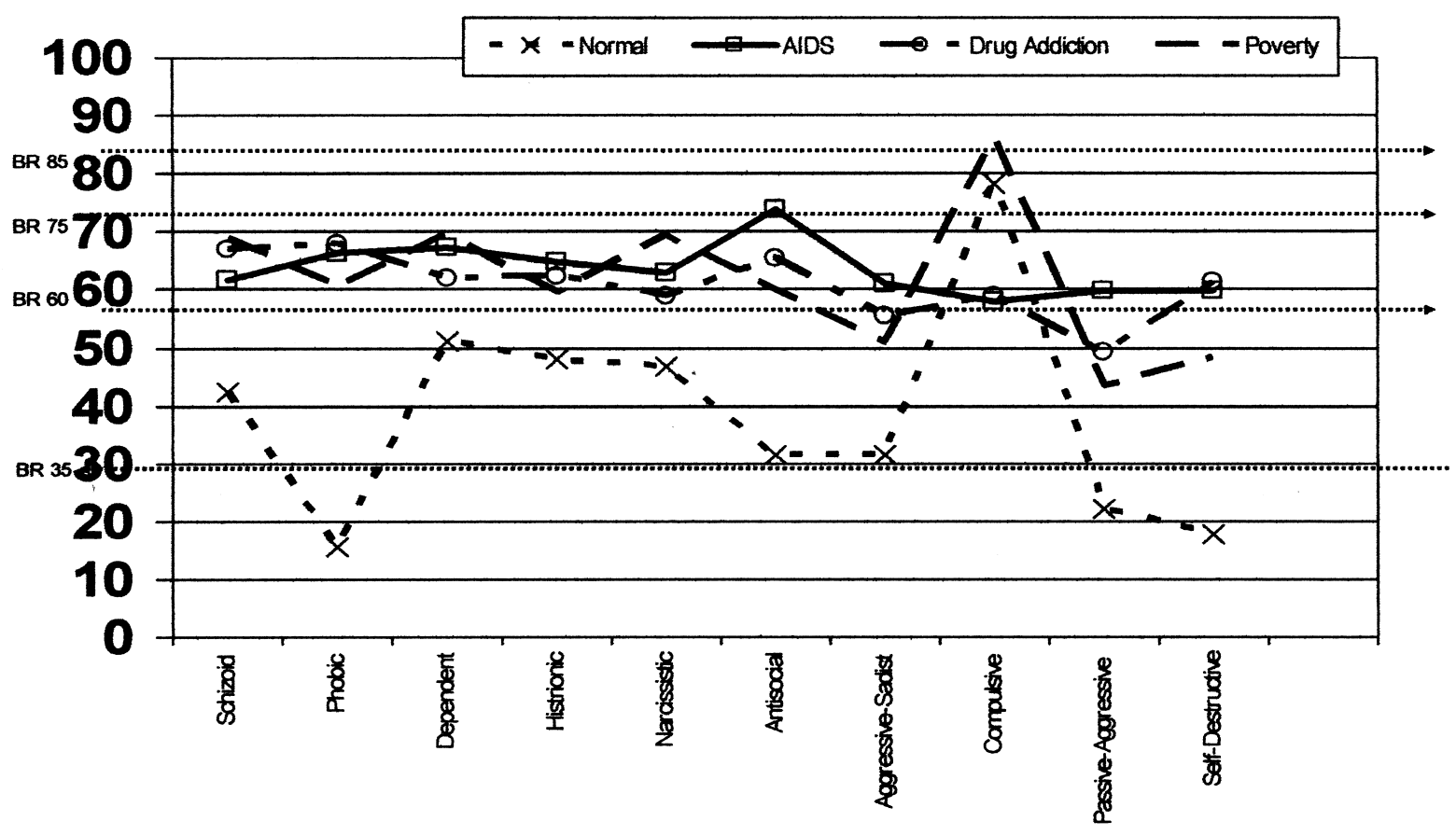

BR 35 Nonclinical subjects' mean score $B R \geq 75$ \& BR 54 Clinically signifcant Personality Disorder traits and behaviors

BR60 Pafent' median score $B R \geq 85$ Diagnosis of Personality Disorder

Figure 1. Mean MCMI-II scores of the normal, AIDS, drug addiction, and poverty groups (BR = Base Rate). 
Table 1

Basic MCMI-II Scales

Basic Personality Scales

Description

1. Schizoid scale

These are individuals characterized by their lack of desire and incapacity to experience pleasure and pain deeply. They tend to be apathetic, distant, and asocial.

2. Phobic scale

These individuals experience few positive reinforcements, proceeding either from themselves or from others. They are vigilant, permanently on guard and they always distance themselves from anxious anticipation of painful aspects of life or reinforcement of negative experiences.

3. Dependent scale

The passive-dependent orientation corresponds with the dependent personality disorder of the DSM-III-R. These subjects have learned to turn to others' leadership as a source of protection and security. They lack initiative and autonomy; parental overprotection is frequent.

4. Histrionic scale

The active-dependent orientation corresponds with the histrionic personality disorder of the $D S M-I I I-R$. The observable style is superficial and enterprising; they manipulate events so as to get more attention and to avoid others' disapproval or lack of interest. They display constant search for stimulation and insatiable affection in each interpersonal relation and context. Their social behaviors are intelligent, giving them an appearance of self-confidence and tranquility.

5. Narcissistic scale

The active-independent orientation is equivalent to the narcissistic personality disorder of the DSM-III-R. These individuals are notable for their selfish attitudes. Early education has taught them to overestimate their own value. They have an air of self-confidence and exploit others capriciously

6.A. Antisocial scale

The active-independent orientation is similar to the antisocial personality disorder. These individuals' behavior is meant to counteract their expectations of pain and other peoples' contempt. They are irresponsible and impulsive. Insensitivity and cruelty are their only means to avoid abuse and deception.

6.B. Aggressive-sadistic scale

The active-discordant orientation extends the limits of the DSM-III-R in a new direction, detecting individuals who are not publicly deemed antisocial, but whose actions lead to satisfaction and personal pleasure by behaviors that humiliate others and violate their rights and feelings. Called aggressive personalities by the author of the theory, they are generally hostile and seem indifferent or even pleased by the destructive consequences of their behaviors.

7. Compulsive scale

The passive-ambivalent orientation coincides with the compulsive personality disorder of the DSM-III-R. Their prudent, controlled, and perfectionist behavior stems from a conflict between their hostility towards others and their fear of social disapproval. Behind this appearance of restriction is intense anger and feelings of opposition which emerge when their control fails.

8.A. Passive-aggressive scale

The active-ambivalent orientation is similar to the passive-aggressive personality disorder of the DSM-III-R. These individuals struggle between following the reinforcement offered $\mathrm{b}$ y others and the reinforcement they desire. They fluctuate between deference and obedience and defiance and aggressive negativism. Their behavior displays a pattern of explosive anger mixed with moments of guilt and shame.

8.B. Self-destructive (Masoquist) scale

The passive-discordant orientation corresponds to the proposal of the DSM-III-R of the self-destructive personality disorder. These persons allow others to exploit them or take advantage of them, stating that they deserve to be shamed and humiliated. In order to integrate their pain and anxiety, which are comforting for them, they remember past events and transform fortunate circumstances into potentially problematic results. They act modestly and try to go unnoticed. 


\section{Results}

In addition to the descriptive studies of all the variables, a one-factor ANOVA was performed. Out of the variables analyzed, only the following personality subscales fulfilled the homogeneity assumption (Lavene's test): the Histrionic scale, $F(3,101)=2.583, p>.05$, the Narcissistic scale, $F(3$, $101)=1.388, p>.05$, and the Aggressive-Sadistic scale, $F(3,101)=0.175, p>.05$. Subsequently, the corresponding ANOVA was performed to compare the groups. As significant differences (at $p<.05$ ) were observed in all the variables employed, multiple post hoc comparisons, using Scheffé's method (assuming equal variances), were performed to determine between which specific groups the differences occurred (see Table 2).

The results obtained revealed that the participants belonging to the drug addiction and AIDS groups had significantly higher levels of histrionic personality and aggressive-sadistic tendencies than the individuals from the normal population.

Nonparametric tests were performed on the variables that did not fulfill the assumption of variance homogeneity: Schizoid scale, $F(3,101)=5.82, p<.001$, Phobic scale, $F(3,101)=4.26, p<.001$, Dependent scale, $F(3,101)=$ $3.03, p<.001$, Antisocial scale, $F(3,101)=2.85, p<.001$, Compulsive scale, $F(3,101)=10.52, p<.001$, PassiveAggressive scale, $F(3,101)=4.21, p<.001$, and SelfDestructive scale, $F(3,101)=8.07, p<.001$. First, a contrast based on Kruskal-Wallis' $H$ test $\left(\chi^{2}\right)$ for several independent samples was performed to determine global group differences.

The results obtained revealed statistically significant group differences in several scales: Schizoid scale, $\chi^{2}(3, N$ $=105)=18.49, p<.0001$, Phobic scale, $\chi^{2}(3,105)=49.56$, $p<.0001$, Antisocial scale, $\chi^{2}(3, N=105)=40.04, p<$
.0001, Compulsive scale, $\chi^{2}(3, N=105)=17.01, p<.001$, Passive-Aggressive scale, $\chi^{2}(3, N=105)=29.84, p<.0001$, and Self-Destructive scale, $\chi^{2}(3, N=105)=49.35, p<$ .0001 .

Subsequently, Mann-Whitney's $U$ test was performed to determine between which specific groups the differences occurred. The detailed results of the group comparisons are displayed in Table 3.

In general, statistically significant differences were observed between the so-called excluded groups and the normal group (see Table 3). Moreover, in the Schizoid scale, there were statistically significant differences between the drug addiction group and the AIDS group. In the Compulsive scale and the Passive-Aggressive scale, there were statistically significant differences between the poverty and the AIDS groups. Lastly, in the Compulsive scale, there were also differences between the poverty group and the drug addiction group.

\section{Discussion}

In general, the data reveal similar scores in practically all the variables that evaluate personality in the socially excluded groups as compared with the normal population. This apparent personality pattern of socially excluded people has been reported in some studies (Barbero, 2002) as a possible predisposing variable of situations of marginality. However, we have not found any investigation that shows prevalence rates of disorders or other personality variables in this population.

Therefore, in order to avoid erroneous conclusions, we have decided to group the differences and their possible explanatory hypotheses as a function of the personality variables under study.

Table 2

Multiple Post Hoc Comparisons of the Basic MCMI-II Scales between the Normal Group and the Poverty, Drug Addiction, and AIDS Groups

\begin{tabular}{llr}
\hline Scale & Group Comparisons & Mean Difference \\
\hline & Normal-Poverty & -11.6000 \\
Histrionic & Normal-Drug Addiction & $-14.5667 *$ \\
& Normal-AIDS & $-16.9667 * *$ \\
& & $-22.6667 *$ \\
Narcissistic & Normal-Poverty & -12.2667 \\
& Normal-Drug Addiction & -16.3667 \\
& Normal-AIDS & -19.1667 \\
Aggressive-Sadistic & & $-23.9333 * *$ \\
& Normal-Poverty & $-29.4000 * *$ \\
\hline
\end{tabular}

$* p<.05 . * * p<.01$. 
Table 3

Mann-Whitney's U Test of the Basic MCMI-II Scales to Establish Differences between the Normal, the Poverty, the Drug Addiction, and the AIDS Groups

\begin{tabular}{|c|c|c|}
\hline Scale & Group Comparisons & $Z$ Value \\
\hline \multirow{4}{*}{ Schizoid } & Normal-Poverty & $-2.807 * *$ \\
\hline & Normal-Drug Addiction & $-3.455^{* *}$ \\
\hline & Normal-AIDS & $-3.136^{* *}$ \\
\hline & Drug Addiction-AIDS & $-1.968^{*}$ \\
\hline \multirow{3}{*}{ Avoidant } & Normal-Poverty & $-4.533 * *$ \\
\hline & Normal-Drug Addiction & $-5.852 * *$ \\
\hline & Normal-AIDS & $-5.955 * *$ \\
\hline \multirow{3}{*}{ Antisocial } & Normal-Poverty & $-2.795 * *$ \\
\hline & Normal-Drug Addiction & $-5.169 * *$ \\
\hline & Normal-AIDS & $-5.717 * *$ \\
\hline \multirow{5}{*}{ Compulsive } & Normal-Poverty & -0.831 \\
\hline & Normal-Drug Addiction & $-2.714 * *$ \\
\hline & Normal-AIDS & $-2.758 * *$ \\
\hline & Poverty-Drug Addiction & $-3.060 * *$ \\
\hline & Poverty-AIDS & $-3.047 * *$ \\
\hline \multirow{4}{*}{ Passive-Aggressive } & Normal-Poverty & $-3.168 * *$ \\
\hline & Normal-Drug Addiction & $-4.163 * *$ \\
\hline & Normal-AIDS & $-4.659 * *$ \\
\hline & Poverty-AIDS & $-2.035 *$ \\
\hline \multirow{3}{*}{ Self-Destructive } & Normal-Poverty & $-4.134 * *$ \\
\hline & Normal-Drug Addiction & $-5.902 * *$ \\
\hline & Normal-AIDS & $-5.888 * *$ \\
\hline
\end{tabular}

$* p<.05 . * * p<.01$.

\section{Schizoid Personality (MT1) and Antisocial Personality (MT6)}

These two variables revealed a similar score pattern. There were no differences between the excluded groups, although there were differences between the excluded groups and the normal group.

According to the DSM IV-TR (American Psychiatric Association, 2002), individuals with a schizoid personality present a general pattern of detachment in their social relations and restricted emotional expression. According to the definition of schizoid personality, these people do not feel any satisfaction of belonging to a family or social group. We especially note the fact that the main feature of this disorder (detached social relations) is precisely what characterizes the groups that scored high on this scale: social exclusion. Hence, we wonder whether the lack of integration in society of the groups that experience social exclusion situations could be explained by the presence of this kind of personality or whether, contrariwise, other variables also affect these scores. This doubtless leads us away from our goal of a detailed analysis of social exclusion, but we believe that social exclusion is so complex and involves so many factors that, although it includes personality variables, the behavior of social exclusion is not sufficiently explained in all cases. In this sense, there were a large number of participants in our sample (90\% of the AIDS group, 36.7\% of the drug addiction group, and $13.3 \%$ of the poverty group) who had decided to participate in social reinsertion programs. Although some people are looking for a purely assistantial solution in these projects, others are trying to achieve the chief goal of these projects: reinsertion (or insertion). This makes us wonder whether the behavior of non-inclusion in the social network is a personality characteristic or whether it also corresponds to other types of complex and multifactorial conditioning factors, as does exclusion itself.

In contrast, the antisocial personality, or disocial disorder, is characterized, among others, by a general pattern of disrespect and violation of others' rights, transgressing rules, and they frequently lack empathy. In our study, there were no significant differences in this scale among the socially excluded groups, but there were differences between the excluded and the normal groups. Moreover, the mean score of the AIDS 
group (73.70) was very close to the cutting point at which it would be considered a clinical trait or behavior-Base Rate (BR) 75-and the mean score of the drug addiction group was higher than $\mathrm{BR}=60$, which is the score established in the MCMI-II (Millon, 1987) as a discriminant of the normality of this subscale. There are various studies where a diagnosis of antisocial personality disorder was made in drug addicts, which corroborate our data. In this sense, Gángara and Medina (1998) found this disorder in $42 \%$ of their sample, and Millon and Davis (2000) found between 30 and 50\%, and they also reported higher frequency of HIV in these individuals.

Millon and Davis (2000) explain the presence of this antisocial disorder in polyaddicts, arguing that people with antisocial disorder do not have the "moral scruples" that might moderate the consumption of substances and are not concerned with the negative consequences of this abuse. In contrast, the immediate gratification that many substances provide matches the tendency of persons with this disorder. Moreover, according to these authors, the consumption of legally forbidden substances involves transgression of a rule, a basic feature of this kind of disorder. Although we may agree that these hypotheses partially explain the behavior of the participants evaluated, however, it does not explain the homogeneity of the groups that consumed drugs (AIDS and drug addiction) compared with the groups that did not (poverty and normal groups).

The absence of differences of the drug addiction/poverty with the no drug addiction/poverty groups, in other words, this homogeneity of the excluded groups, could be due to various aspects. On the one hand, one of the biggest difficulties in the study of psychopathic traits is that lying and manipulation are core features of the disorders and, therefore, responses are not very reliable. That is, some people may not acknowledge consuming drugs when the opposite is true, thus producing homogeneity. On the other hand, the error may be in the diagnosis, as some behaviors are similar to the antisocial disorder and may be erroneously diagnosed as such. The first differential behavior is delinquency. Although people with an antisocial personality tend to commit unlawful acts, most individuals who break the law do not present antisocial traits (especially as they feel guilty). Another behavior that may obstruct diagnosis derives from the substance-related disorder, because of the large number of transgressions of rules these individuals present, obviously due to their addiction. In fact, Millon and Davis (2000) conclude that the DSM criteria for antisocial disorder may not be capable of discriminating individuals with true traits from those whose behavior is a consequence of their drug dependence.

Once again, we find a series of behaviors that can be labeled antisocial disorder and that, in fact, correspond to adaptative or normal behaviors in certain situations of social exclusion. In fact, environmental factors-certain family situations, such as prolonged maternal deprivation, family fights, separations, antisocial paternal behavior, or the situation of social exclusion-have been suggested as possible etiological influences that may contribute to the development of an antisocial personality disorder (Saiz, 2002).

The lack of development of basic abilities that determine certain behaviors classified under the antisocial label may be the skills that were not "worked on" and were therefore not developed in people who live in a situation of social exclusion. If so, people whose situation of social marginality has fomented their incapacity to tolerate boredom, their unreflective responses, low frustration tolerance, and irresponsible behavior (all features of antisocial disorders according to the DSM-IV-TR) may-according to the current categorical systems - be diagnosed as having an antisocial disorder when, in fact, they are experiencing a situation of social exclusion.

\section{Phobic Personality (MT2)}

In this personality variable, the groups behaved similarly to the previous variables, that is, with homogeneous scores in the socially excluded groups as compared with the normal group.

The most important clinical features of the avoidant personality are fear of scorn and desire to be accepted, because of which these individuals adopt an attitude of constant vigilance for possible contempt and have few social relations.

We have not found any works that provide prevalence rates of this personality trait in the groups studied. The research reviewed focused on the avoidant coping style, which is not comparable to the trait studied here. However, in our study, the scores of the socially excluded groups revealed considerable presence of this trait. We believe that it is to be expected and it is even adaptative for excluded people to be afraid of being looked down on and to wish to be accepted. Again, behaviors that can be considered as belonging to a personality trait can also be considered to be adaptative behavior in persons who undergo a situation of social marginality.

\section{Dependent Personality (MT3)}

According to the $D S M-I V-T R$, the behavior pattern of dependent persons consists of searching for relationships where they can find support, obtain affection, security, advice, sometimes submitting to the desires of others to achieve them. These individuals are passive and allow others to take the initiative and to assume responsibility for essential decisions in their lives. They also have difficulty expressing their point of view when they disagree with someone.

Although, visually, the means of the groups from our study may seem different, the statistical analyses showed that none these differences between any of the four groups were statistically significant. This similar behavior of the different groups may be due to several causes. However, upon observing the means and standard deviations, despite the absence of significant differences, the participants from the normal group scored lower than $\mathrm{TB}=60$, cutting-point of 
the MCMI-II to determine the presence of this variable. It seemed relevant to explain why participants from the socially excluded groups had scores that indicate the presence of this personality pattern. A possible explanation for one of the groups is offered by Millon and Davis (2000), who suggest that individuals with a dependent personality may present higher rates of infection from HIV because they may have difficulty refusing to perform high risk behaviors if imposed on them by their partner. We suggest various possibilities for the excluded groups: These persons have often lacked stable family references, growing up in a situation of abandon. This can lead to the search for this reference in their relations, so that, when they do find a partner, they are willing to give in so as not to lose the partner. This foments relations of mutual dependence where the relation itself is frequently a constant source of conflict, but it is the only reference point they have. Institutionalization may also be a modulating variable in this personality pattern. Thus, the participants had a history of living in institutional centers (penitentiaries, assistantial centers, rehabilitation centers, therapeutic centers, etc.) sometimes for over 20 years' duration. Although in some centers, the development of the person is enhanced, other centers still follow the assistantial-paternalist model, which, in addition to making people more infantile, also makes them dependent.

\section{Histrionic Personality (MT4)}

People with this personality pattern display a generalized and excessive expression of emotions, and a behavior of constantly seeking attention, affection, favors, sometimes even manipulating events to avoid other peoples' disapproval and lack of interest (DSM-IV-TR).

Our data show a uniform behavior in the socially excluded groups. A possible explanation may be found in the manipulative and delinquent behaviors that are a part of the street subculture and of drug addiction. It seems reasonable to think that people who have lied and blackmailed others in order to survive or who have broken the law for many years will continue to do so even when it is not necessary. And people who attend centers where services and support are provided tend to exaggerate their neediness so as to continue to receive aid. However, in many cases, peoples' social and personal situations are so precarious that the constant search for attention and affection corresponds to their basic needs, which have not been met for many years.

\section{Narcissistic Personality (MT5)}

This personality pattern is characterized by generalized grandiose behavior, the need for admiration, and lack of empathy, which are underlie low self-esteem, according to the DSM-IV-TR.

In our samples, again, the three socially excluded groups present statistically similar scores, with notably higher scores in the poverty group. However, although generally, the scores do not reach the relevant values to be considered an explanatory variable of these groups' behavior, we believe that these groups may present some narcissistic attitude that may be considered adaptive.

Some authors (Millon \& Davis, 2000) have mentioned that the feelings of invulnerability associated with the narcissistic personality make these individuals feel that it is unnecessary to adopt preventive measures against HIV/AIDS and, therefore, they may present higher rates of infection. Although we do not question this possible explanation for the general population of people infected by HIV, we believe that in the collective of our study, other factors provide the explanation because the groups that are not infected have the same scores as those who are. Hence, we believe that the narcissistic attitude may be due to an outward show to defend themselves from constant attacks on their self-esteem, either external attacks (social rejection) or self-attacks (feelings of reproach, guilt, and impairment). We believe this possible defense may sometimes be adaptive, as long as it is moderate, as in our sample.

However, it is noteworthy that only the poverty group presented statistically significant differences with the group of normal population. A possible explanation is that, among the various subpopulations that make up the complex reality of exclusion, those that do not have certain problems (i.e., drugs, AIDS) may perceive themselves as being somewhat superior, because in their reference group (social exclusion), their situation is not quite so unfavorable.

\section{Compulsive Personality (MT7)}

High scores in this variable in the MCMI-II indicate that the individuals feel forced to accept conditions that others impose on them. It refers, ultimately, to self-discipline, which sometimes conceals an inner feeling of resistance (Millon \& Davis, 2000).

The scores of our study in this variable were surprising, as it was the only one where the criterion "presence of drugs" discriminated. That is, the groups that did not use drugs (normal, poverty) presented statistically similar scores that were both different and higher than the scores of groups that did use drugs (drug addiction, AIDS). The low scores of this variable in the drug-user groups and their difference with the remaining groups may be explained by the high levels of impulsiveness in polyaddicts (Millon \& Davis, 2000), and this is the possible cause of these individuals' low self-control, and therefore, of their low compulsiveness.

Aggressive-Sadistic Personality (MT6B), PassiveAggressive Personality (MT8A), and Self-Destructive Personality (MT8B)

These three aggressive personality patterns behaved similarly in our sample, following the tendency of most of the personality variables, that is, the scores of the socially 
excluded groups were similar in comparison to those of the normal population group (although somewhat lower in the Aggressive-Sadistic scale). However, the difference in the remaining variables is for the central tendency of the scores in practically all the measures to be lower than $\mathrm{TB}<60$, the cutting point established in the MCMI-II to indicate the presence of the variable.

We found no data, either in our own experience or in the scientific literature reviewed, that lead us to assume that some of the features of these personality patterns are present in the population under study. Despite the differences with the normal group, the scores obtained by the socially excluded groups do not indicate the present of the features of this personality pattern.

To conclude, and taking into account all the above about personality variables, in our study, despite the fact that persons who are undergoing a social exclusion situation generally present similar scores in the variables studied, this does not clearly indicate the existence of a personality profile in the excluded population. Rather, it indicates that there are certain situations that cause the excluded groups to present similar behaviors, and these behaviors do not always correspond to personality traits, but are instead adaptive responses to a complex and harsh reality.

We therefore point out the need for studies that address the reality of social exclusion specifically and exhaustively, as well as multidimensionally, in order to contribute hypotheses to help clarify which are the possible psychological variables that foment and/or maintain the processes of social exclusion. If research is carried out only using diagnostic categories, while ignoring the reality of social exclusion and with no profound knowledge about it, then we would be committing errors - such as, for example, establishing the existence of a personality pattern in socially excluded persons on the basis of the results of this studywhich would only foment social exclusion.

\section{References}

American Psychiatric Association (1980). Diagnostic and statistical manual of mental disorders ( $3^{\text {rd }}$ ed.). Washington, DC: Author. (Spanish translation: Manual diagnóstico y estadístico de los trastornos mentales: DSM-III. Barcelona: Masson, 1981.)

American Psychiatric Association (1987). Diagnostic and statistical manual of mental disorders ( $3^{\text {rd }}$ ed. text revision). Washington, DC: Author. (Spanish translation: Manual diagnóstico y estadístico de los trastornos mentales: DSM-III-TR. Barcelona: Masson, 1988.)

American Psychiatric Association (2000). Diagnostic and statistical manual of mental disorders ( $4^{\text {th }}$ ed.). Washington, DC: Author. (Spanish translation: Manual diagnóstico y estadístico de los trastornos mentales: DSM-IV-TR. Barcelona: Masson, 2001.)

American Psychiatric Association (2002). Diagnostic and statistical manual of mental disorders ( $4^{\text {th }}$ ed. text revision). Washington,
DC: Author. (Spanish translation: Manual diagnóstico y estadístico de los trastornos mentales: DSM-IV-TR. Barcelona: Masson, 2002.)

Ayuso, J.L. (1997). Trastornos neuropsiquiátricos en el SIDA. Madrid: McGraw-Hill.

Ayuso, J.L., Lastra, I., \& Montañés, F. (1995). SIDA en el enfermo psiquiátrico. In J. Cadafalch (Coord.), SIDA y drogodependencias (pp. 95-107). Madrid: Ediciones en Neurociencias.

Barbero, J. (2002). SIDA, exclusión e intervención psicosocial. Perspectiva teórica, In M.J. Rubio \& S. Monteros (Coords.), La exclusión social. Teoría y práctica de la intervención (pp. 129-148). Madrid: Editorial CCS.

Benschop, R.J., Jabaaij, L., Oostveen, F.G., Vingehoets, J.J.M., \& Bailliex, R.E. (1998). The influence of psychological stress in immunoregulation of latent Epstein-Barr virus. Stress Medicine, 14, 21-24.

Brooner, R.K., Herbst, J.H., \& Schmidt, C.W. (1993). Antisocial personality among drug abusers: Relations to other personality diagnoses and the Five-Factor model of personality. Journal Nervous Mental Disease, 181, 313-319.

Combs, D.R., \& Livingston T. (2001). Psychological sub-types among persons with HIV infection: An empirical study. AIDS Care, 13, 157-162.

Eysenck, H.J. (1985). Personality, cancer and cardiovascular disease: A causal analysis. Personality and Individual Differences, 6, 535-556.

Flores, E. (2004). Alteraciones emocionales, variables de personalidad y estrategias de afrontamiento en personas afectadas por SIDA. Unpublished doctoral dissertation. University of Seville, Spain.

Fuste, E., \& Ruíz, J. (2000a). Análisis de la relación entre personalidad, estrategias de afrontamiento, estrés percibido y respuesta inmune a una prueba de hipersensibilidad retardada. Ansiedad y Estrés, 6, 169-189.

Fuste, E., \& Ruíz, J. (2000b). Personalidad y salud: aproximación desde una perspectiva psiconeuroinmunológica. In J. Gil (Coord.), Manual de psicología de la salud. Volumen II: Comportamiento y salud/enfermedad (pp. 280-302). Madrid: Ediciones Némesis.

Gándara, J.J., \& Medina, M.A. (1998). Comorbilidad. In M. Bernardo \& M. Roca (Comps.), Trastornos de la personalidad: evaluación y tratamiento. Perspectiva psicobiológica. Barcelona: Masson.

Iraurgi, I. (2003). El estrés y los estresores de ser positivo al VIH antes y después de la terapia antirretroviral de alta eficacia. Publicación Oficial de la Sociedad Española Interdisciplinaria del SIDA, 14, 5. Madrid. http://seisida.rediris.es/html/sei_my03.htm

Jacobsberg, L., Frances, A., \& Perry, S. (1995). Axis II diagnoses among volunteers for HIV testing and counseling. American Journal of Psychiatry, 152, 1222-1224.

Jemmot, J.B., \& Locke, S.E. (1984). Psychosocial factors, immunological mediation and human susceptibility to infectious diseases: How much do we know? Psychological Bulletin, 95, 78-108. 
Kwang, L.J., Han, L.Ch., Byung, P.D., Seok, K.B., Chul, N., Sik, L.Y., Yeon, Ch.J., Woo, N.B., Hong, L..K., \& San, Ch.D. (1998). Circulating natural killer cell in neurotic patients. International Medical Journal, 5, 121-126.

Lluch, J., Salvador, L., Gatell, J., \& Cirera, E. (1989). Diagnóstico psiquiátrico en pacientes con SIDA ingresados en un hospital general. Medicina General, 7, 277-278.

Millon, T. (1987). Millon Multiaxial Inventory (MCMI-II) (Spanish adaptation: Ávila-Espada, A., \& Jiménez, F.: MCMI-II. Inventario Clínico Multiaxial de Millon-II. Madrid: TEA Ediciones, 1999.).

Millon, T., \& Davis, R. (2000). Personality disorders in modern life. New York: Wiley (Spanish translation: Trastornos de la personalidad en la vida moderna. Barcelona: Masson, 2001).

Navia, B.A., \& Price, R.W. (1987). The acquired immunodeficiency syndrome dementia complex as the presenting or sole manifestation of human immunodeficiency virus infection. Archives of Neurology, 44, 65-69.

Perkins, D., Davidson, E., Leserman, J., Liao, D., \& Evans, D. (1993). Personality disorder in patients infected with HIV: A controlled study with implications for clinical care. American Journal of Psychiatry, 150, 309-315.
Pérez, M., Sáez, H., \& Trujillo, M., (2002). Pobreza y exclusión social en Andalucía. Córdoba: Instituto de Estudios Sociales de Andalucia. Roitt, I. (1971). Roitt's essential immunology. Oxford: Blackwell. (Spanish translation: Inmunología esencial. Barcelona: Ediciones Jims, 1981).

Rundell, J.R., Wise, M.G., \& Ursano, R.J. (1986). Three cases of AIDS-related psychiatric disorders. American Journal of Psychiatry, 143, 6, 777-778.

Saiz, J. (2002). Trastorno de la personalidad en la práctica médica. Barcelona: Masson.

Salvador, L., Lluch, J., \& Ayuso, J.L. (1995). Aspectos neurológicos y psiquiátricos del SIDA. In J. Cadafalch (Coord.), SIDA y drogodependencias (pp. 57-94). Madrid: Ediciones en Neurociencias.

Thornton, S., Tropo, M., \& Burgess, A.P. (2000). The relationship of psychological variables and disease progression among longterm HIV-infected men. International Journal of STD and AIDS, 11, 734-742.

Valverde, J. (1996). Vivir con la droga. Madrid: Pirámide.

Received: July 30, 2004 Review received: January 27, 2005 Accepted: February 4, 2005 